\title{
Snow fences on slopes at high wind speed: physical modelling in the CSTB cold wind tunnel
}

\author{
F. Naaim-Bouvet, M. Naaim, and J.-L. Michaux \\ Cemagref, Torrent and Avalanche Research Unit, 2 rue de la Papeterie, BP 76, F-38402 Saint-Martin-d'Hères, France
}

Received: 20 September 2001 - Accepted: 31 January 2002

\begin{abstract}
In order to determine the effect of steep slopes on snowdrift generated by snow fences, we have conducted physical modeling experiments in the CSTB (Centre Scientifique et Technique du Bâtiment) cold wind tunnel as part of the European project "Access to Large Facilities". After an overview of previous studies and an accurate description of the drifting snow process inside the experimental chamber, we present the main results obtained. (1) On flat areas, even for high wind speed, the acknowledged results for moderate wind are still valid: the porous snow fence (50\%) is the most efficacious and the bottom gap increases the efficacy of the dense snow fence. (2) The steeper the slope is, the less effective all tested snow fences are. Their effectiveness decreases considerably: the snow catch is approximately divided by two for a slope of $10^{\circ}$. (3) Contrary to flat areas, on steep slopes, the "efficacy" is greater for a dense snow fence.
\end{abstract}

\section{Notation}

$A$ is a planform drift area $\left(\mathrm{m}^{2}\right), L$ is the reference length (m), $H$ is the reference height $(\mathrm{m}), \lambda$ is the length of the ablation zone (m), $C_{D}$ is the drag coefficient, $D_{p}$ is the particle diameter $(\mathrm{m}), g$ is the gravitational acceleration $\left(\mathrm{ms}^{2}\right), \rho$ is the air density $\left(\mathrm{kgm}^{-3}\right), \sigma$ is the particle density $\left(\mathrm{kgm}^{-3}\right), \gamma$ is the bulk density of the deposited snow $\left(\mathrm{kgm}^{-3}\right), t$ is time (s), $\bar{v}_{i}$ is the mean velocity component in the $O_{i}$ direction $\left(\mathrm{ms}^{-1}\right)$, $U$ is the reference speed (m), $U_{0}$ is the threshold speed at a reference height $\left(\mathrm{ms}^{-1}\right), U_{F}$ is the particle settling velocity $\left(\mathrm{ms}^{-1}\right), u_{*}$ is the shear velocity $\left(\mathrm{ms}^{-1}\right), u_{* t h}$ is the erosion threshold shear velocity $\left(\mathrm{ms}^{-1}\right), p$ is pressure $\left(\mathrm{Nm}^{-2}\right)$.

\section{Introduction and objectives of the studies}

Fences are usually used for prevention of snowdrifts on roads. Many data are available, including wind-tunnel and

Correspondence to: F. Naaim-Bouvet

(florence.naaim@cemagref.fr) outdoor experiments. They have dealt with the shape of the snow-drift generated by different snow fences on flat terrain for moderate wind speeds $\left(6-10 \mathrm{~m} / \mathrm{s}^{-1}\right)$ : the optimum design has been determined. But snow fences could also be used to prevent cornice formation upwind of the avalanche-prone path. In this last case, snow fences are erected in high mountain areas on upwind slopes near the crest, which is generally submitted to high wind speed. Research dealing with snow fences on slopes is scarce due to various experimental problems: the size of the wind tunnel and the need to use real snow. The large "Jules Verne" cold wind tunnel at CSTB has solved these problems. We therefore used this wind tunnel to simulate snowdrifts generated by different types of snow fences on various slopes.

After an overview of the previous studies related to snow fences on slopes and to similitude requirements, the experimental set-up, measurement devices and experiments will be presented. The first part of the experiments was specifically dedicated to the study of drifting snow inside the experimental chamber of the CSTB cold wind tunnel. The second part of the experiments was done to compare the different snow fence models under the same wind, rate of snow supply, storm duration, temperature and humidity conditions on different slopes.

\section{Previous studies}

\subsection{Snow fences on slopes}

Research dealing with the interaction between snow fences on slopes is scarce and often incomplete. According to Tabler (1991), snowdrift is very sensitive to the slope: a windward slope leads to a decrease in storage capacity, whereas a leeward slope leads to an increase. But no large measurement studies support this analysis. Nevertheless, the physical experiments in water flumes done by Issaenko have strengthened these observations. In this last case, the wind alone was studied: the author focused on the modification 


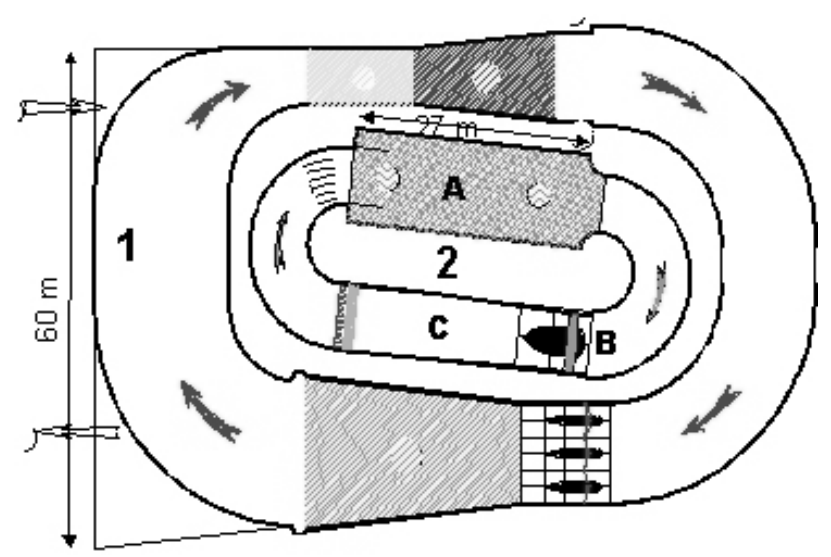

Fig. 1. Jules Verne climatic wind tunnel: (1) Dynamic circuit; (2) Thermal circuit with experimental chamber (A $90-140 \mathrm{~km} / \mathrm{h}, 25^{\circ} \mathrm{C}$ to $+50^{\circ} \mathrm{C}$ ), fan (B $1000 \mathrm{~kW}$ ) and cold and warm heat exchangers (C).

of the wake generated by a solid fence set up on a windward slope ranging from $0^{\circ}$ to $45^{\circ}$. The length of the wake was approximately $10 \mathrm{H}, 9 \mathrm{H}, 6 \mathrm{H}, 4 \mathrm{H}, 2.5 \mathrm{H}$ for a slope of $0^{\circ}, 10^{\circ}$, $20^{\circ}, 30^{\circ}$ and $45^{\circ}$, respectively, with $H$ as the height of the snow fence. We also found these orders of magnitude in an abacus (Naaim-Bouvet and Brugnot, 1992) and when dealing with the optimum spacing between dense hedges: $10 \mathrm{H}$, $3.3 \mathrm{H}, 2.5 \mathrm{H}$ for a slope of $10^{\circ}, 11.5^{\circ}$ and $17^{\circ}$, respectively. Sarret (1993) has reported on scale-model experiments performed in Quebec dealing with snow fences on slopes, using natural snow and wind as the modeling material and the driving force. Unfortunately, he only tested one configuration without knowing the reference wind speed.

\subsection{Physical modeling: similitude requirements}

Physical modeling allows to the study snowstorms in smallscale laboratory models. However, the validity of full-scale prediction (drift patterns and storm duration) from smallscale experiments by using similarity criteria remains difficult since the large number of modeling parameters cannot be satisfied. Many experiments have been carried out by several scientists; but difficulties lie in the disagreement between authors over the most important and appropriate sets of modeling requirements. The different points of view in this matter will be examined. If the use of the following requirements - reducing geometrical dimensions to the same scale, obtaining turbulent model flow and matching the angle of repose between model and prototype materials - are approved unanimously, important divergences concerning wind speed and storm duration criteria appear within the scientific community.

\subsubsection{Wind speed criteria}

Some authors (Iversen (1980, 1984), Kind (1986), Tabler (1980) recommend the use of the Froude number $U^{2} / H G$, the densimetric Froude number $\left(\rho U^{2}\right) /(\sigma g H)$ or the modified densimetric Froude number $\left(\rho U^{2}\left(1-U_{0} / U\right)\right) /(\sigma g H)$, whereas Anno (1984) proposes using $u_{*} / u_{* t h}$. The Froude number derives from the particle trajectory equation of motion. In this case, it is closely linked to $\left(C_{D} \rho H\right) /\left(\sigma D_{p}\right)$ : if both parameters are satisfied, it is not possible to reduce significantly the scale of the prototype using air as the model fluid. According to our own wind tunnel results (Naaim-Bouvet, 1995), the Froude number by itself is not a relevant parameter and the wind speed ratio $\left(u_{*} / u_{* t h}\right)$ is more appropriate. Moreover, if the two requirements $U^{2} / H g$ and $\left(C_{D} \rho H\right) /\left(\sigma D_{p}\right)$ are satisfied, the wind speed ratio $u_{*} / u_{* t h}$ is automatically matched between model and prototype (Naaim-Bouvet, 1997).

\subsubsection{Storm duration criteria}

The most common parameter is $(\rho U t) /(\sigma H)$ or $(\rho U t) /(\gamma H)$ (Kind, 1986; Tabler, 1980). But particles or wind speeds differ from erosion or deposition speeds. In fact, $(\rho U t) /(\sigma H)$ has physical foundations only if the previous requirements are satisfied simultaneously (NaaimBouvet, 1997): $U^{2} / H g,\left(C_{D} \rho H\right) /\left(\sigma D_{p}\right)$, (derived from the particle trajectory equation of motion) and the dimensionless drift rate $\rho / \sigma\left[1-U_{0} / U\right]\left[U^{2} /(g H)\right]\left[\left(U_{t}\right) / H\right]$ (derived from the mass rate of motion of saltating particles). As we said previously, reduction of the scale is small in this case. The dimensionless drift rate was introduced by Iversen (1980). This approach appeared to be truly innovative. After a first proposal $\left[\left(u_{*} t\right) / L\right]\left[\left(\rho u_{*}^{2}\right) /(\sigma g H)\right]\left[1-u_{* t h} / u_{*}\right]$, he suggested a more general form in which he used an analytic expression of $\mathcal{J}$ which must be determined thanks to wind tunnel experiments:

$$
\begin{aligned}
& \frac{A}{L^{2}}=\left(\frac{u_{*} t}{L}\right) \frac{\rho u_{*}^{2}}{\sigma g H}\left(1-\frac{u_{* t h}}{u_{*}}\right) \times \\
& \mathcal{J}\left(\frac{u(H) L}{V}, \frac{h}{H}, \frac{l}{L}, \frac{z_{0}}{H}, \frac{z_{0^{\prime}}}{H}, \frac{\rho}{\sigma}, \frac{U_{F}}{u_{* t h}}, \frac{u_{*}^{2}}{g H}\right) .
\end{aligned}
$$

In fact, in order to take into account the influence of the length $\lambda$ of the erosion area inside the wind tunnel, it is necessary to introduce it in a function of $\mathcal{J}$ (Naaim-Bouvet and Naaim, 1997)

\section{Accurate description of the drifting snow process in the CSTB cold wind tunnel}

\subsection{Cold wind tunnel}

The Jules Verne climatic wind tunnel was built in order to conduct full-scale experiments. It has two independent circuits (Fig. 1): the first is a dynamic circuit and the second one, called the thermal circuit, is able to create hot or cold climates (from $-25^{\circ} \mathrm{C}$ to $+50^{\circ} \mathrm{C}$ ) with snow, sun, rain, freezing rain or frost. The temperature, the relative humidity (from $30 \%$ to $95 \%$ ) and the wind speed are controlled. In this circuit, the test section has the following dimensions: length, 

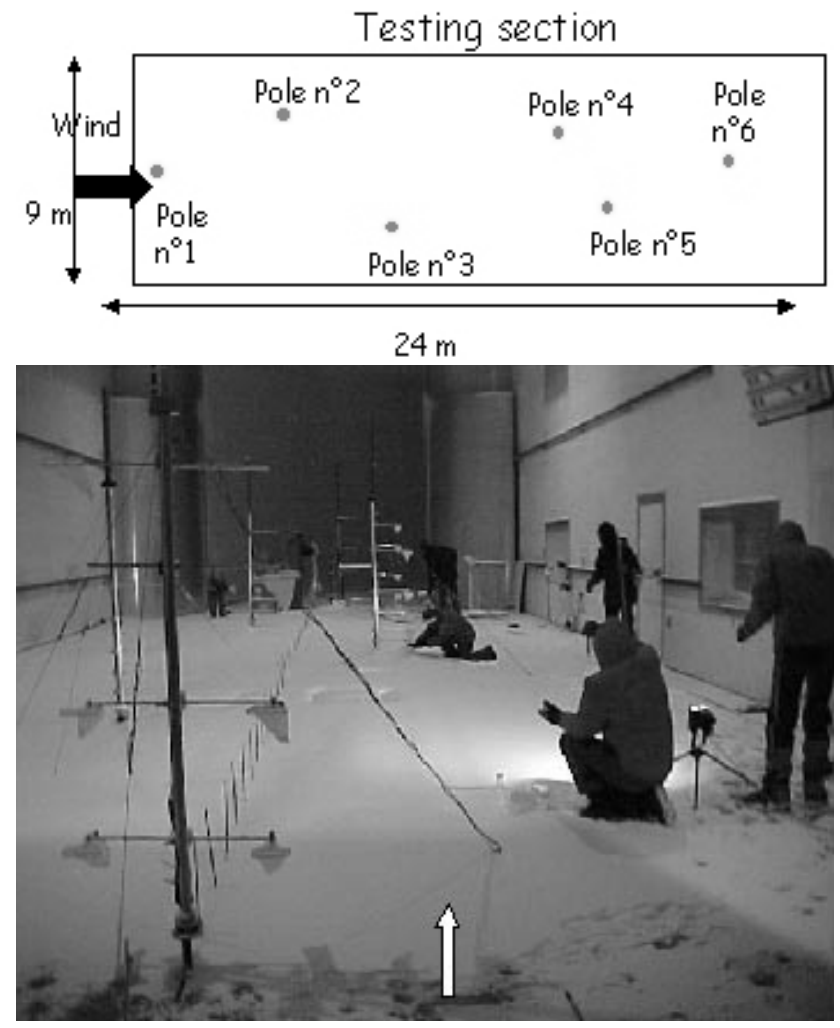

Fig. 2. Experimental set-up in the testing section.

$27 \mathrm{~m}$, height, $8 \mathrm{~m}$ and width, $10 \mathrm{~m}$. Snow is produced by snow guns that project compressed air and water in the ambient air of the wind tunnel in order to obtain ice droplets. The experimental devices of the climatic wind tunnel are able to create snow mantles of about $100 \mathrm{~mm} / \mathrm{h}$ on a $200 \mathrm{~m}^{2}$ area. The quality of the snow produced is adjustable by controlling the air and water flows in the snow gun.

4.2 Study of drifting snow in the experimental chamber: problems encountered

The first part of the experiments was specifically dedicated to the study of drifting snow inside the experimental chamber, which has never been done before. The testing section was equipped with six poles with different types of sensors: a wind anemometer (poles no. 1, no. 5, no. 6), acoustic drifting snow sensors and drifting snow mechanical trap profiles (poles no. 1-6), and a thermometer (pole no. 4) (Fig. 2).

The acoustic snowdrift sensor is a miniature microphone located at the base of a 2-m high aluminium pole. During snowdrift, the pole is exposed to the snow-particle flux and part of the flux impacts on the pole. The sound produced by these impacts is recorded as an electrical signal on the data logger.

Mechanical snow traps, called butterfly nets, determine mass flux. These have a rectangular metal frame $(15 \mathrm{~cm} \times$ $2 \mathrm{~cm}$ ) with an attached nylon bag. The traps, facing the prevailing wind direction, are fixed at different altitudes on a pole, next to the acoustic sensor. After the drifting snow

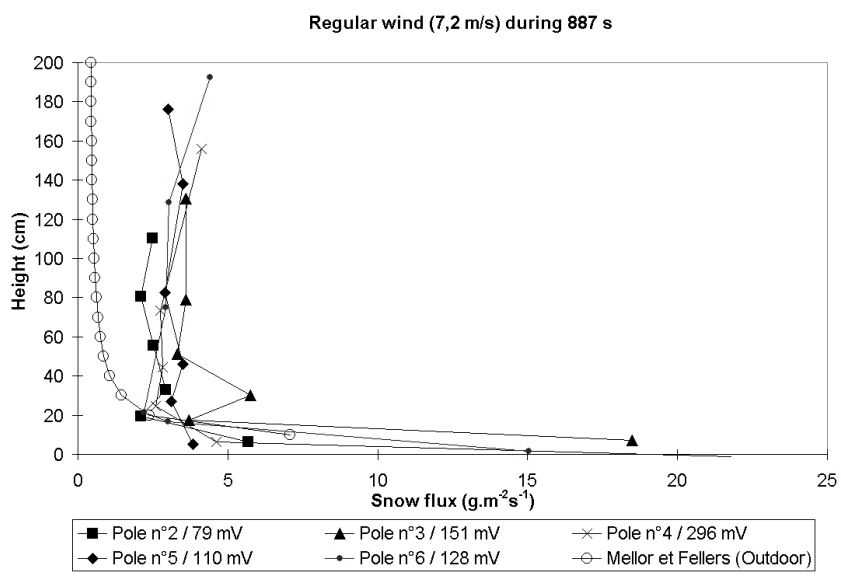

Fig. 3. Mean snow flux (without snowfall) as a function of height for wind speed of $7.2 \mathrm{~m} / \mathrm{s}$ (values in $\mathrm{mV}$ correspond to data recorded by the acoustic sensor) in wind tunnel.

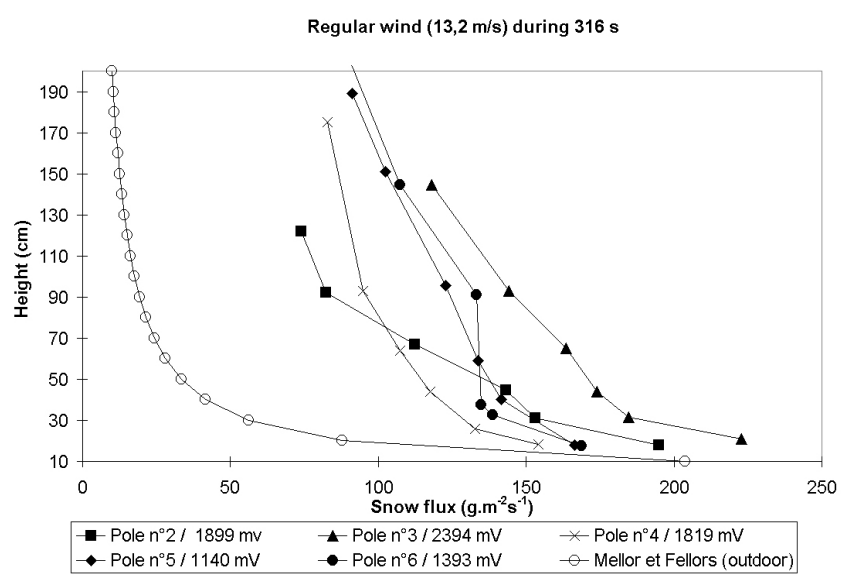

Fig. 4. Mean snow flux (without snowfall) as a function of height for wind speed of 13.2,/s (value in $\mathrm{mV}$ corresponds to data recorded by the acoustic sensor) in wind tunnel.

event, contents of traps are weighed. The collection efficiency of such mechanical traps depends on the wind speed and can be below $100 \%$. Lacking further information, no correction is applied.

Additional measurements are made before and after the drifting snow event: snow temperature, density and shear stress.

\subsubsection{Heavy recirculation of drifting snow}

We studied two possible scenarios: wind blown while the snow guns were in operation, which represents drifting snow with snowfall, and wind blown after the snow guns had stopped, simulating drifting snow without snowfall.

Figures 3-5 show the relation between the measured snow mass flux and the height for the different pole positions in the cold wind tunnel. Mellor and Fellers (1986) have established empirical formulae linking snow mass flux and height 


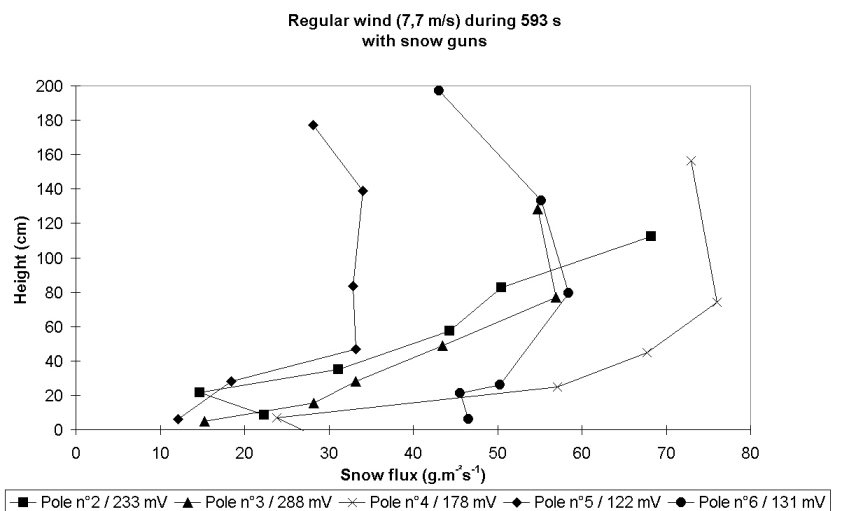

Fig. 5. Mean snow flux as a function of height for wind speed of $7.7 \mathrm{~m} / \mathrm{s}$ while snow guns are in operation (values in $\mathrm{mV}$ correspond to data recorded by the acoustic sensor) in wind tunnel.

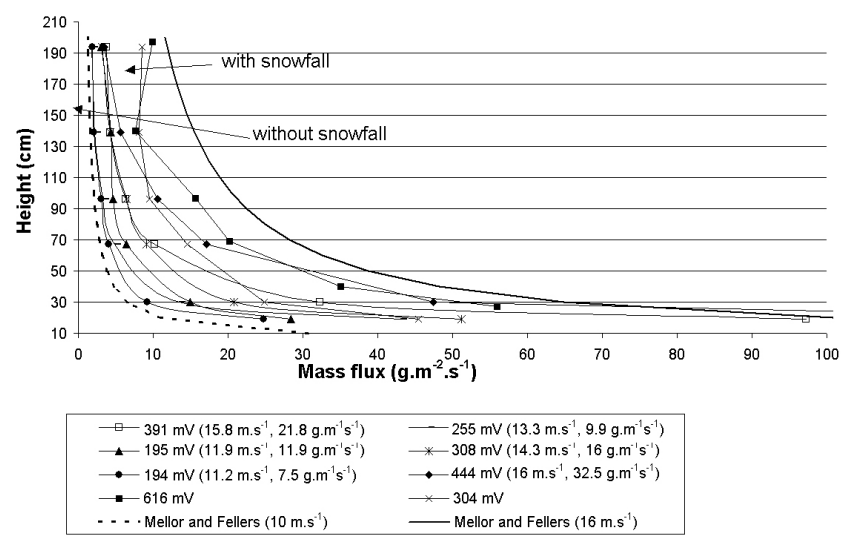

Fig. 6. Mean snow flux as a function of height for different natural drifting snow events at Lac Blanc Pass.

from experimental data processing carried out in Antarctica. These empirical curves are drawn on the same graphs. Data observed at our alpine experimental site (Michaux et al., 2001) and presented in Fig. 6 fit quite well with the value reported in Mellor and Fellers (1980), even though they did not distinguish the effect of snowfall in their data processing. The analysis of these four graphs shows that:

- the simulation of a drifting snow event with simultaneous snowfall is unrealistic in the CSTB wind tunnel (Figs. 5 and 6): when the snow guns and the wind tunnel work simultaneously, snowdrift is no longer a decreasing function of height.

- the simulation of a drifting snow event without simultaneous snowfall seems to be quite good. The orders of magnitude are respected for the two tested speeds $(7.2 \mathrm{~m} / \mathrm{s}$ and $13.2 \mathrm{~m} / \mathrm{s})$ in the lower part of the curve. This means the saltation is simulated correctly and the fetch is sufficiently long to obtain saturation. Nevertheless, it was observed that the mass flux in the diffusion

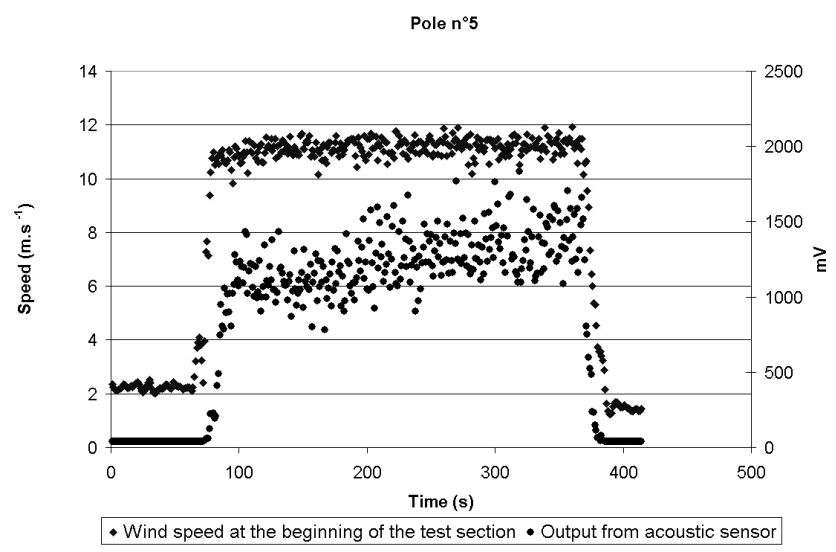

Fig. 7. No snow in the recirculation zone: the time to obtain steadystate blowing snow is long.

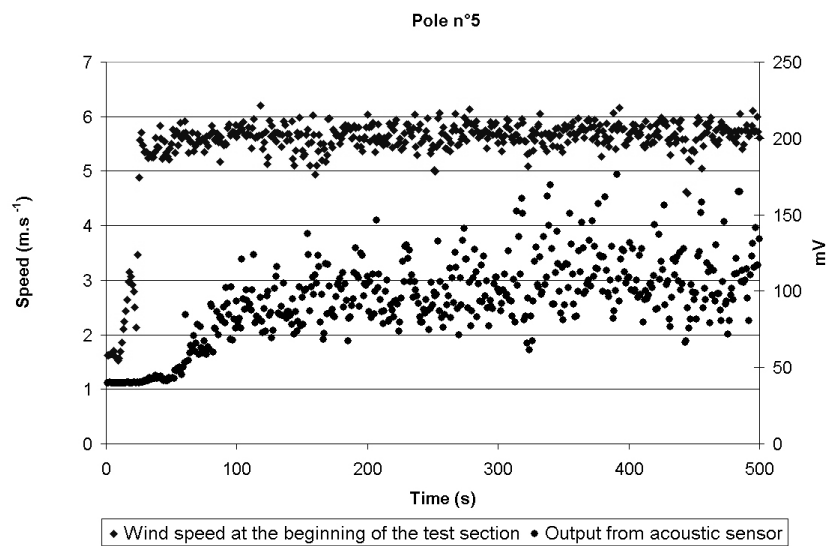

Fig. 8. Snow in the recirculation zone: the time to obtain steadystate blowing snow is shorter.

layer (the higher part of the curve) is more substantial in the case of wind tunnel simulation. In fact, the cold wind tunnel is a return flow with a closed circuit type and the lack of filter leads to the permanent presence of a small-particle cloud during all the trials: the higher the speed is, the greater the cloud (Figs. 3 and 4).

Previous figures deal with the mean snow flux. However, if we study carefully the instantaneous snow flux with the acoustic drifting snow sensors, we can also observe that the recirculation zone acts upon the time to obtain saturation.

For snow, Kobayashi (1972) showed from experimental data that the fetch necessary to obtain saturation ranged from 30 to $60 \mathrm{~m}$. Takeuchi (1980) estimated that the snowdrift flux reached saturation about $350 \mathrm{~m}$ downwind of the starting point. Even if the dimensions of the cold wind tunnel are substantial (more than $20 \mathrm{~m}$ for the erosion zone), it is probably not enough to obtain saturation after only one air passageway through the test section. Since there was no filter in the recirculation zone ( $\mathrm{C}$ on Fig. 1), the air flow was loaded progressively with snow particles after several revo- 


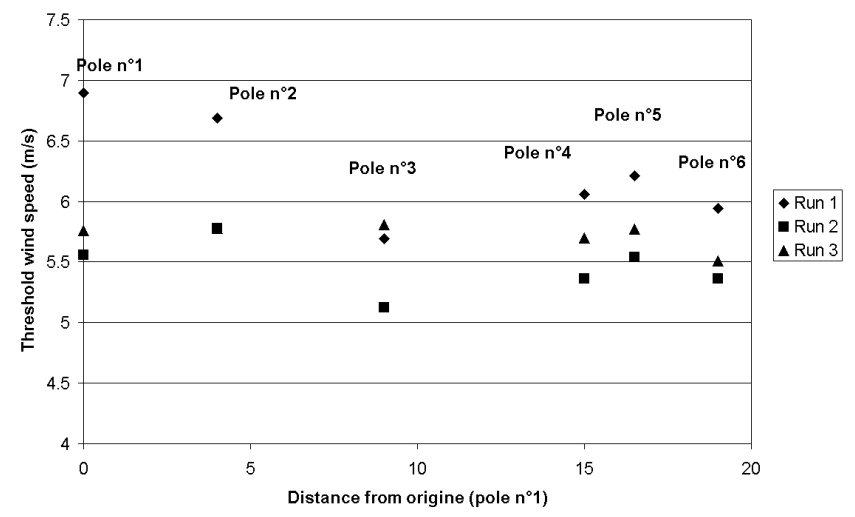

Fig. 9. Threshold erosion velocity as a function of the distance from the snow gun.

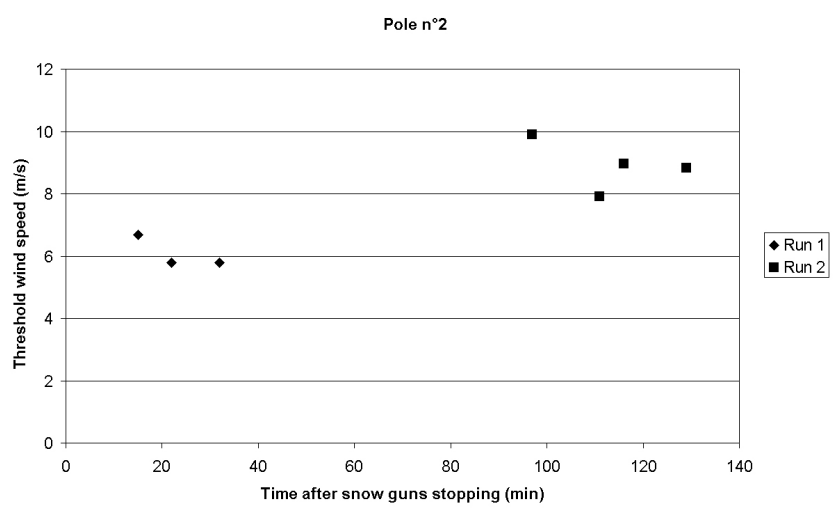

Fig. 10. Threshold erosion velocity as a function of time.

lutions inside the wind tunnel. At the beginning of the day, there was no snow in the recirculation zone (Fig. 7) because the wind tunnel was cleaned at the end of each day. But at the end of the day, there was a lot of snow in the recirculation zone, so that the length of ablation zone was increased artificially and the time to obtain the steady state was shortened (Fig. 8).

\subsubsection{Dissymmetry of blowing snow}

From a theoretical point of view, snow flux must be an increasing function of the length of the erosion zone (meaning the distance from the snow gun). This theoretical approach is not validated by the measured snow flux profiles drawn on Figs. 3 and 4. In fact, the poles did not stand in a straight line along the experimental chamber (see Fig. 2) so that one pole would not be in another pole's wake. Actually, the right side (in the stream direction) of the experimental chamber seemed to be submitted to more drifting snow (see poles no. 3 and 5 in Figs. 3 and 4), leading to a dissymmetry in the testing section.

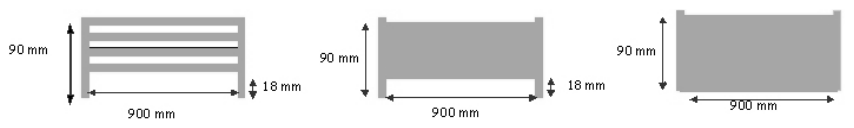

Fig. 11. Small-scale models of snow fences.

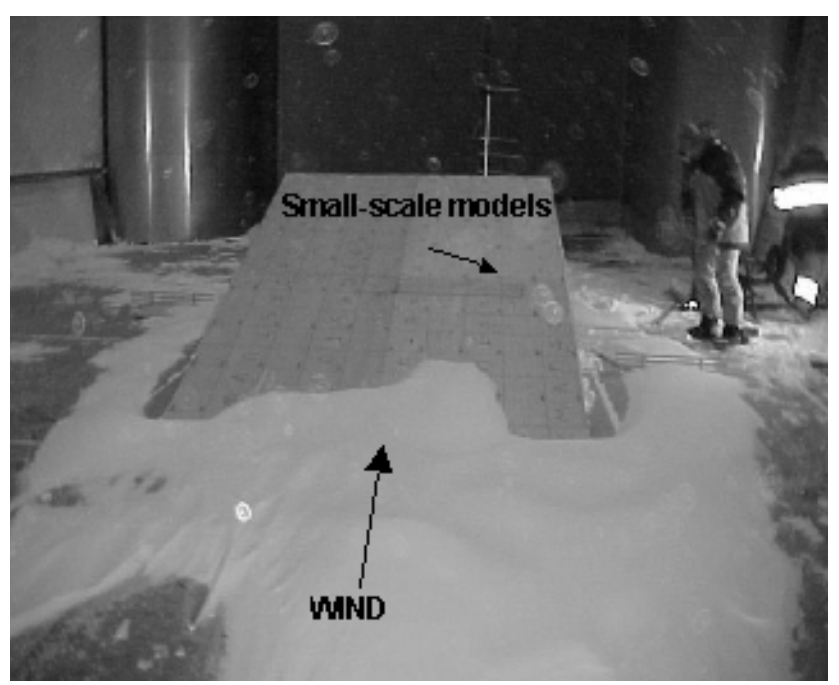

Fig. 12. Experimental set-up in the test section.

4.2.3 Variation of threshold erosion velocity as a function of distance from the snow guns

The size of snow particles, which are quite spherical, varied from 250 to $400 \mu \mathrm{m}$ and decreased all along the test chamber due to the trajectories of water droplets. Moreover, the snow temperature decreased according to the distance from the snow gun (Guyomarc'h and Pugliese, 2001). The magnitude of variation reached a high of $6^{\circ} \mathrm{C}$ for a distance of $8 \mathrm{~m}$. From a theoretical point of view, the combination of these factors must lead to a decreasing threshold erosion velocity depending on the distance from the snow gun. The experimental measurements (see Fig. 9) validate this assumption, but we can note that the threshold difference between the beginning and the end of the experimental chamber was only a maximum of $1 \mathrm{~m} / \mathrm{s}$.

\subsubsection{Variation of threshold velocity as function of time}

Binocular observations (Boisseau-Kouznetzoff and Palier, 2001) of snow produced by snow guns show that the cloud is formed of quite spherical particles, whose diameters were analysed by a phase Doppler particle analyzer, and varied from 150 to $450 \mu \mathrm{m}$. Artificial snow seems to be equivalent to a natural snow which has been drifted by wind. In this case, the particles are typically small ice grains; if snow transport was deposited from wind transport, cohesive bonds between particles must be broken to start movement again.

A laboratory experiment summarized by Hobbs (1974) related the bond growth of sintering ice spheres to time $t$ and 


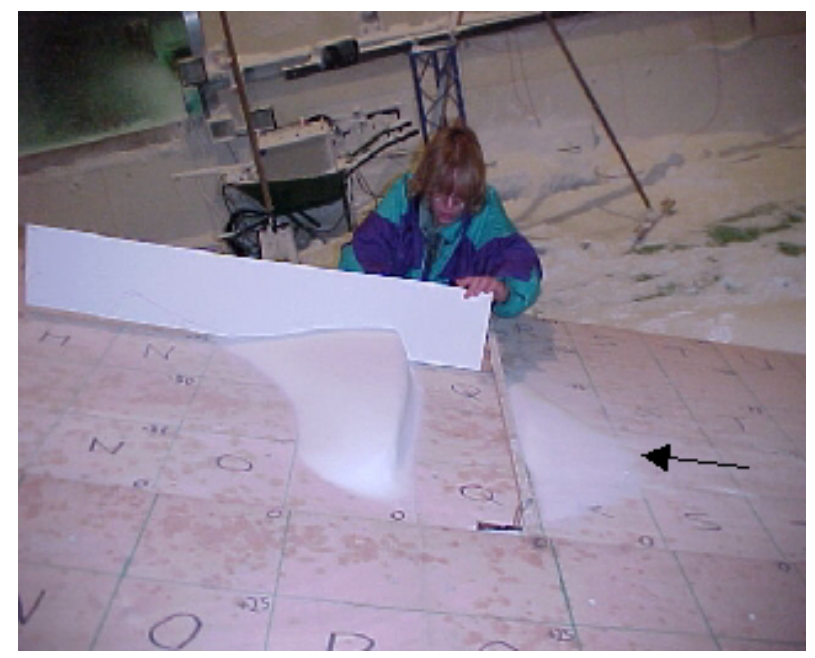

Fig. 13. Determination of snowdrift shape at the end of an experiment.

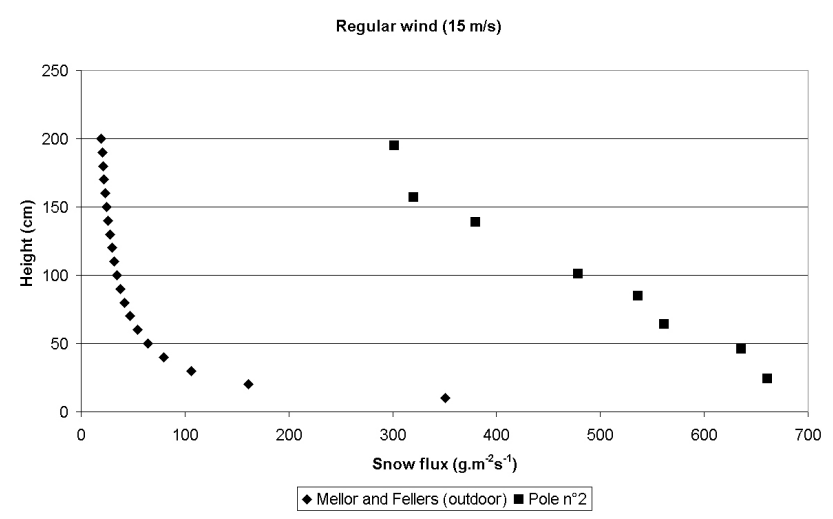

Fig. 14. Mean snow flux as a function of height during the experiment.

temperature $T$, according to the relation:

$\left(\frac{x}{R}\right)^{5}=\frac{B(T) t}{R^{3}}$,

where $x$ is the bond radius, $R$ is the ice particle radius, and $B(T)$ is a function of temperature.

So, when particle movement starts again, bond strength has increased so that interparticle bonds cannot be broken by wind forces that initiated previous transport; higher threshold speeds or other forces are required. Measured cohesion decreases exponentially with decreasing temperature and increases with humidity (Schmidt, 1980).

All of these results mean that after snow guns stop operating and before the beginning of the runs, the threshold velocity must vary as a function of time. This hypothesis has been confirmed by the following experiments, whose results are depicted in Fig. 10.

Two identical experiments were done: we operated the three snow guns with a low wind speed (between 2 and $3 \mathrm{~m} / \mathrm{s}$ ) at $-15^{\circ} \mathrm{C}$ for approximately $20 \mathrm{~min}$, in order to obtain a quite

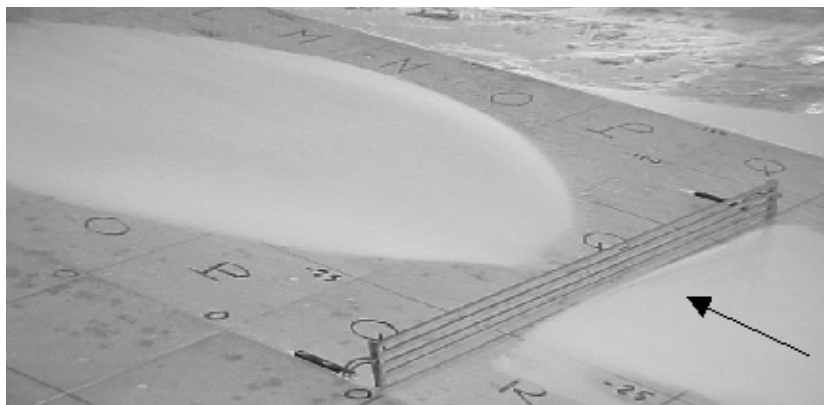

Fig. 15. Porous snow fence on a $10^{\circ}$ slope after $8 \mathrm{~min}$.

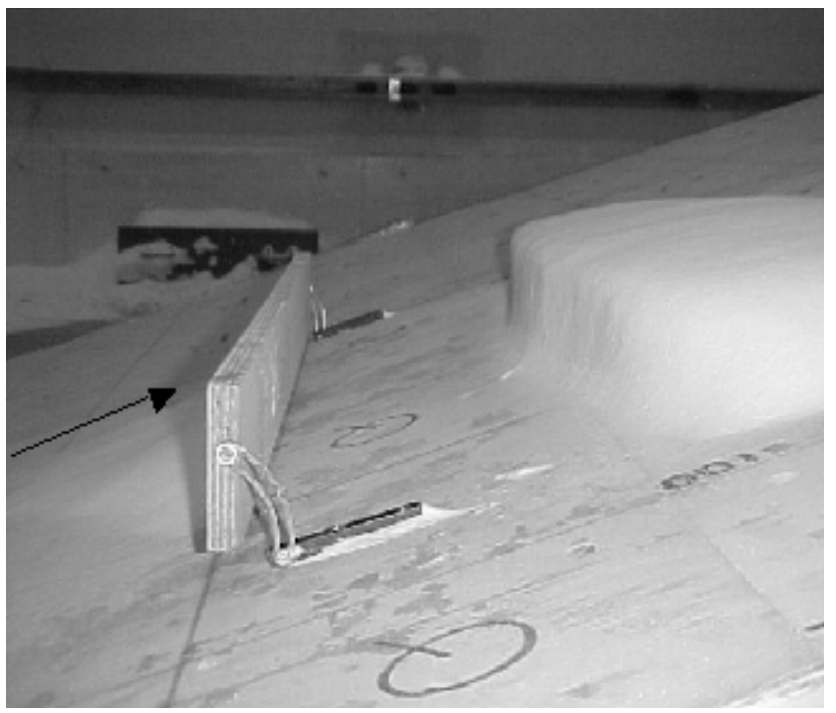

Fig. 16. Dense snow fence on a $17.5^{\circ}$ slope after $8 \mathrm{~min}$.

consequential and uniform snow depth. After a waiting period of $12 \mathrm{~min}$ for the first set of data (run 1) and $97 \mathrm{~min}$ for the second set of data (run 2), we determined the threshold velocity at pole no. 2. After a first increase in wind speed above the threshold speed, the speed was decreased below the threshold speed so that it would be possible to determine the threshold velocity again, and so on. First, we noted that the greater the waiting time is, the greater the threshold velocity, which is in accordance with the theory. Second, for each experiment, the first recorded threshold velocity after the waiting period was greater than the others: cohesive bonds between particles had been broken to start movement during the first drifting snow event and there was not enough time before the following event to allow for new bonds to form.

\section{Experimental set-up for snow fence studies}

These experiments were done to test the influence of windward slope on snowdrift shape generated by different models of snow fences under the same wind, rate of snow supply, duration of storm, temperature and humidity conditions. A 


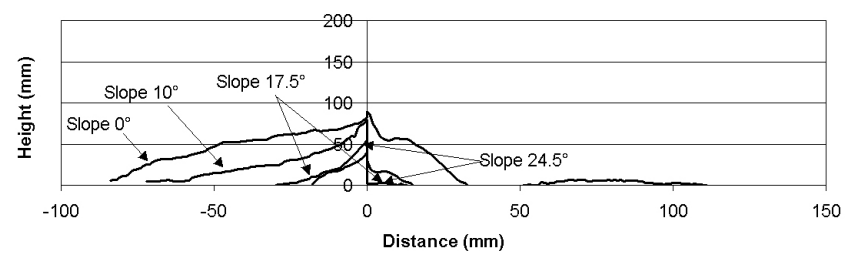

Fig. 17. Snow catch of a dense snow fence without bottom gap after 8 min of experiment.

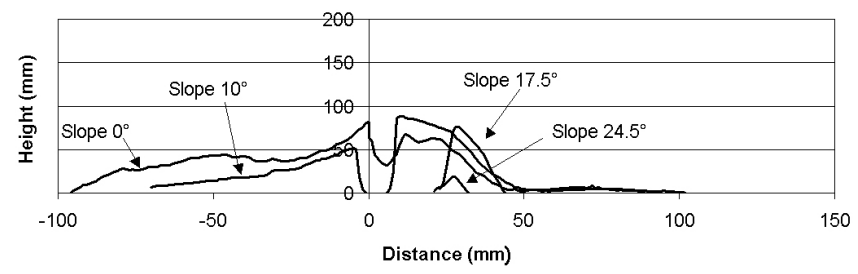

Fig. 18. Snow catch of a dense snow fence with bottom gap after 8 min of experiment.

better understanding of cold wind tunnel characteristics, presented previously, allowed us to optimise the experimental setup.

Very large dimensions of the wind tunnel were used to study the snow fence on different slopes $\left(0^{\circ}, 10^{\circ}, 17.5^{\circ}\right.$ and $24.5^{\circ}$ ). Different types of snow fences (porous, dense, with and without bottom gap) were tested (see Fig. 11) under the same laboratory conditions. The slope consisted of a wood plate $2.5 \mathrm{~m}$ wide, $6 \mathrm{~m}$ long, and in two pieces: the upwind slope was $4 \mathrm{~m}$ long and the downwind slope was $2 \mathrm{~m}$ long (Fig. 12). The wood plate was centred in the experimental chamber and the width of the plate was reduced in order to avoid the effect of dissymmetry in the testing section.

Small-scale models, $90 \mathrm{~cm}$ in width, were mounted on the floor and placed vertically and perpendicular to the flow and the plate axis, and were set up $175 \mathrm{~cm}$ from the slope's beginning. Small-scale models were not centred on the plate but positioned on the right side, so that we could study the effect of the slope on its own in snowdrift formation (Fig. 12).

The experimental procedures were as follows: first, we operated the three snow guns with a low wind speed (between 2 and $3 \mathrm{~m} / \mathrm{s}$ ) at $-15^{\circ} \mathrm{C}$ for approximately $20 \mathrm{~min}$, in order to obtain a quite consequential and uniform snow depth. Then, immediately after stopping the guns, snow traps were set up, the data loggers were initialized and the wind tunnel speed was increased rapidly up to its working value, which was kept constant at $15 \mathrm{~m} / \mathrm{s}$. We chose a high working value $(15 \mathrm{~m} / \mathrm{s})$ in order to reach the near equilibrium heights for a short duration, so that the threshold velocity (and all snow characteristics) would remain the same during the entire test. The maximum duration of a run was $8 \mathrm{~min}$ and the value of the similitude requirement $u_{*} / u_{* t h}$ was approximately 2 . When the drift was formed, the snow height was determined manually by drawing the snowdrift shape (see Fig. 13) along

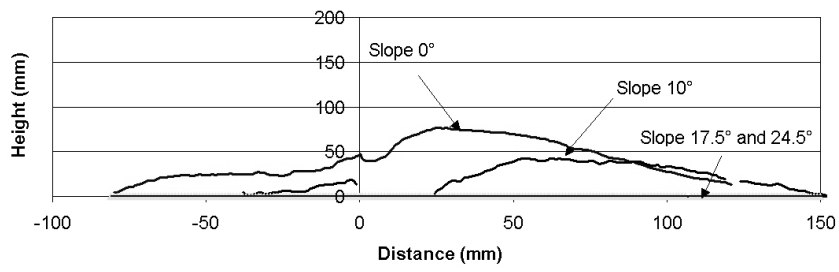

Fig. 19. Snow catch of a porous snow fence with bottom gap after 8 minutes of experiment.

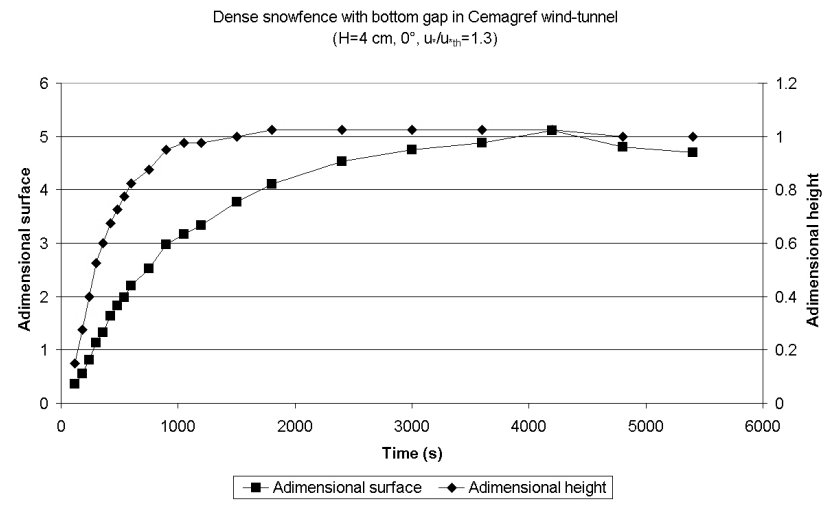

Fig. 20. Dimensionless maximum depth and dimensionless area as a function of time for a sand drift generated by a dense snow fence $(40 \mathrm{~mm})$ with a bottom gap $(8 \mathrm{~mm})$ in the Cemagref wind-tunnel $\left(u_{*} / u_{*} t=1.3\right)$.

the main axis $(Y=0 \mathrm{~cm})$ and the right-hand side of the axis $(Y=-25 \mathrm{~cm})$. The longitudinal profiles along these lines were later measured. The measurements were repeated after each interruption of the wind tunnel, in order to determine the rate of accumulation and the shape of the drift on the leeward and windward sides. A typical mean snow flux as a function of height at the entry of the experimental chamber is shown in Fig. 14. Views of the experiment are shown in Figs. 15 and 16.

\section{Main results}

Cross-section profiles are shown for the four slopes and the three small-scale snow fence models in Figs. 17, 18 and 19. First of all, the obtained snowdrifts in the wind-tunnel were not at equilibrium. It can be seen from the data obtained in the wind tunnel (Naaim-Bouvet and Naaim, 1998) that the downwind drift volume for early times increased nearly linearly with time and then much more slowly after that, until reaching equilibrium drift (Fig. 20). The same tendency is seen for the dimensionless maximum height. But the equilibrium drift seems to have been reached earlier, so that the maximum height cannot be a sufficient indication to conclude that the profile is the equilibrium profile (Fig. 20).

Now, if we carefully study the dimensionless area as a function of time for the snowdrift generated by the three different small-scale models on the four slopes (Fig. 21), it can 


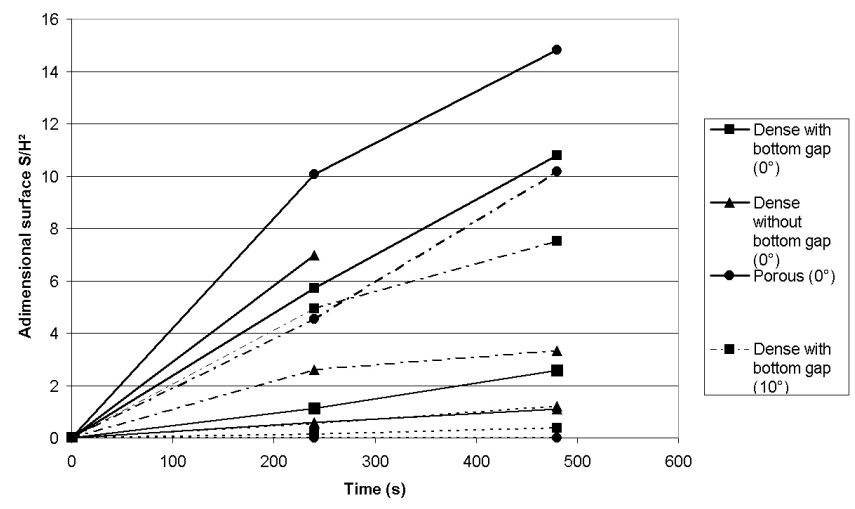

Fig. 21. Dimensionless area as a function of time for the snowdrift generated by the three different small-scale models on the four slopes.

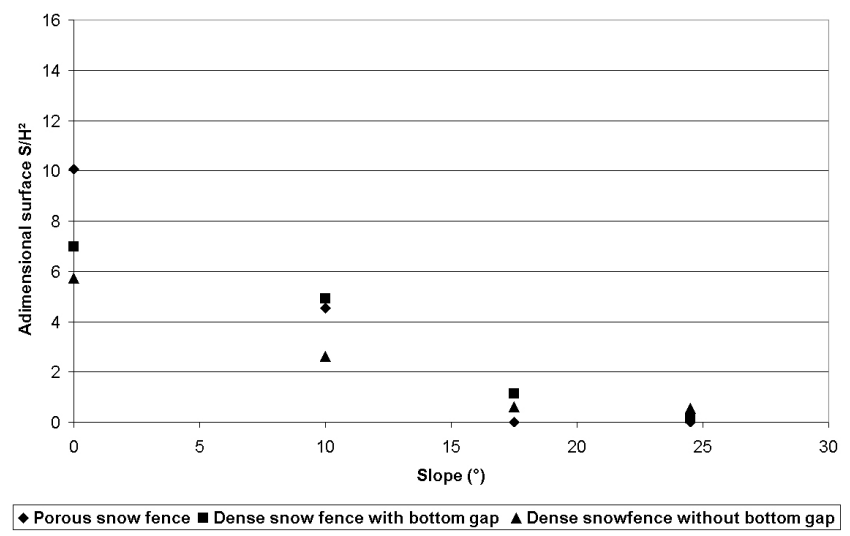

Fig. 22. Adimensional surface of the snowdrift as a function of slope after $4 \mathrm{~min}$.

be seen that the drift volume increased linearly with time, which is a typical feature of an intermediate drift profile.

For practical reasons and particularly for a zero slope, it was not possible to carry on with the experiments in order to obtain equilibrium: after $8 \mathrm{~min}$, the snow layer was almost completely eroded (see Fig. 12), so that the snow flux was no longer constant during the experiment. Moreover, the snow in the erosion zone, moving by reptation (see Fig. 12), reached the snow fence and buried it. This was already visible in Fig. 19 for the $0^{\circ}$ slope. But it was not the case for experiments lasting $4 \mathrm{~min}$.

Thus, these short experiments were not extended to saturation; consequently, direct comparison with the equilibrium drift could not be made. Nevertheless, the slope of the curves depicted in Fig. 21 are representative of snow fence efficacy.

It can be seen from the data in Figs. 22 and 23 that:

- on a flat area, even for high wind speed, the acknowledged results for moderate wind were still valid: the porous snow fence $(50 \%)$ was the most efficacious and

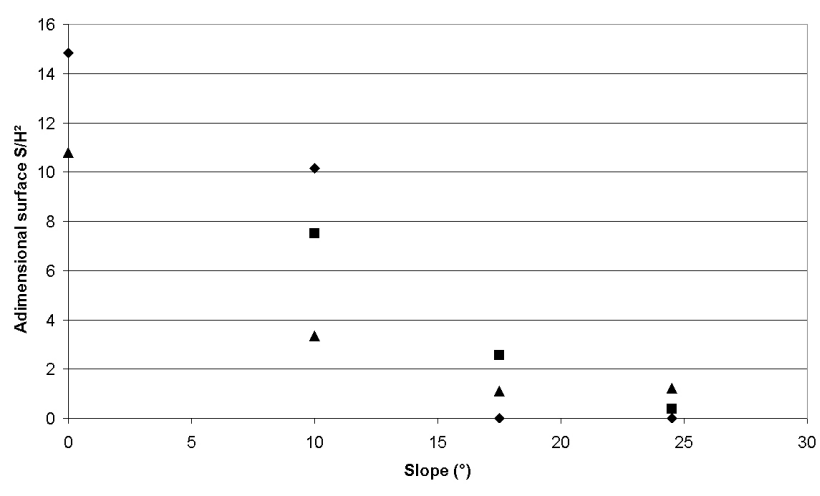

$\downarrow$ Porous snow fence $\square$ Dense snow fence with bottom gap $\triangle$ Dense snowfence without bottom gap

Fig. 23. Adimensional surface of the snowdrift as a function of slope after $8 \mathrm{~min}$.

the bottom gap increased the efficacy of the dense snow fence.

- the steeper the slope is, the lower the degree of efficacy is for all tested snow fences. It decreased considerably: the snow catch was approximately divided by two for a slope of $10^{\circ}$.

- for a steep slope, the efficacy is greater for a dense snow fence; there was no longer any accumulated snow downstream of a porous snow fence on a slope of $17.5^{\circ}$.

\section{Conclusions and further developments}

This study shows that the slope could have a substantial effect upon the choice of the snow fence type and where it is implanted. It seems that dense fences are more suitable for steep slopes at high wind speed. Nevertheless, the obtained snowdrifts in the wind-tunnel were not at equilibrium: more investigations are necessary also using numerical simulations of wind flow around fences, which will be the subject of further publications.

Acknowledgements. This research was supported by European Union (CHM/LSF/noERBFMGECT980144). The authors gratefully acknowledge the assistance of G. Guyomarc'h, P. Pugliese (CEN-Meteo France) and F. Ousset (Cemagref) for preparing experiments and collecting data, M. Dufresne de Virel, O. Viau and P. Delpech (CSTB) for operating the wind tunnel and equipments, $S$. Haraldsdottir (IMO-Iceland) for helping in the measurements and L. Heiligenstein (Cemagref) for processing data.

\section{References}

Anderson, R. S. and Haff, P. K.: Wind modification and bed response during saltation of sand in air. Aeolian Grain Transport, Acta Mechanica 1, Springer Verlag, 21-52, 1991.

Anno, Y.: Requirements for modeling a snowdrift, Cold Region Science and Technology, 8, 241-252, 1984. 
Boisson-Kouznetzoff, S. and Palier, P.: Qualification of snow produced in climatic wind tunnel/Qualification de la neige produite en soufflerie climatique, International Journal of Refrigeration, 24, 302-324, 2001.

Gandemer, J.: La soufflerie climatique Jules Verne Climatic Wind Tunnel, J. of Wind Engineering Aerodynamique, 43-54, 1992.

Gandemer, J., Palier, P., and Boisson-Kouznetzoff, S.: Snow simulation within the closed space of the Jules Verne Climatic Wind Tunnel, Proceedings of the Third International Conference on Snow Engineering, Snow engineering: Recent Advances, A. A. Balkema Publishers, 347-352, 1997.

Guyomarc'h, G. and Pugliese, P.: Rapport des mesures effectues dans la soufflerie climatique du CSTB de Nantes, Internal Report, Meteo France, 2001.

Hobbs, P. V.: Ice Physics, Oxford, Clarendon Press, 1974.

Iversen, J. D.: Drifting snow similitude: transport rate and roughness modeling, J. of Glaciology, 26, 94, 393-403, 1980.

Iversen, J. D.: Comparison of snowdrift modeling criteria : commentary on Application of Anno's modeling conditions to outdoor modeling of snowdrifts, Cold Regions Science and Technology, 9, 259-265, 1984.

Kind R. J., Snowdrifting: a review of modeling methods, Cold Region Science and Technology, 12, 217-228, 1986.

Kobayashi, S.: Studies of snow transport in low-level drifting snow. Contributions from the Institute of Low Temperature Science, series A, 24, 1-58, 1972.

Michaux, J. L., Naaim-Bouvet, F., and Naaim, M.: Drifting-snow studies over an instrumented mountainous site: II. Measure- ments and numerical model at small scale, Annals of Glaciology, 32, 175-181, 2001.

Mellor, M. and Fellers, G.: Concentration and flux of wind-blown snow, CRREL Spec. Rep. 86-11, 1980.

Naaim-Bouvet, F. and Brugnot, G.: Transport de la neige par le vent: connaissances de base et recommendations, Cemagref/Division Nivologie ISBN 2-85362-312-2, 1992.

Naaim-Bouvet, F.: Comparison of requirements for modeling snowdrift in the case of outddor and wind-tunnel experiments, Survey in Geophysics, 16, 5-6, 711-727, 1995.

Naaim-Bouvet, F.: Contribution à la modélisation physique et numérique du transport de neige par le vent, $\mathrm{Ph} . \mathrm{D}$ thesis, University of Grenoble, 1997.

Naaim-Bouvet, F. and Naaim, M.: Snowdrift modeling in wind tunnel: vertical and horizontal variation of the snow flux, Annals of Glaciology, 26, 212-216, 1998.

Sarret, F.: Modélisation des congères à l'extérieur et en soufflerie", Mémoire de 3ième année, ENGEES, Cemagref, Université de Chicoutimi, 1993.

Schmidt, R. A.: Threshold wind-speed and elastic impact in snow transport, J. of Glaciology, 26, 94, 453-467, 1980.

Tabler, R. D.: Self-similarity of wind profiles in blowing snow allows outdoor modeling, J. of Glaciology, 26, 94, 421-433, 1980.

Tabler, R.: Snow fence guide, National Research Council Strategic Highway Program, Washington, 1991.

Takeuchi, M.: Vertical profile and horizontal increase of drift-snow transport, J. of Glaciology, 26, 94, 481-492, 1980. 